\title{
ENGINEERING RISK OF SERIES PRODUCTION IN AUTOMOTIVE INDUSTRY
}

\author{
Dan Mihai POPA \\ Politehnica University of Timisoara
}

\begin{abstract}
:
The global objective of this paper is to analyze engineering risk of series production in Automotive Industries based on problems caused by supplied chain of products when a strong process to avoid engineering risk problems is missing. Automotive Industries Companies in Romania use just some theoretical tools like as D-FMEA (Design - Failure Mode and Effect Analysis) for engineering risk in their design products in ADAS domein. The main causes appear after the production starts and sometimes it brings the production to a halt. The risks reveal details of different levels and high risk can be caused by unforeseen challenges during of series production. On this paper, the method for engineering risk of management used is based on project management guide by Paul Roberts adapted to causes identification and risk plan.
\end{abstract}

Key words: ADAS, engineering of risk management, engineering risk, risk management, risk assessment

\section{INTRODUCTION}

On the incipient phase of project, on quotation project a lot of times risk planning is not taken in consideration by management engineering, because on Automotive Industry in Romania the standards such as: IATF 16949, ISO 31000 and ISO 31010, are left aside because in the quotation phase is very hard to find a risk assessment evaluator and is too expensive to pay for this type of evaluation. In fact, this quotation can be lost into the detriment of another competitors, not from financial reasons, but from technical causes (product performance) of planning causes (final delivery to customer).

The preponderant tendency in automotive industry is to adapt permanently to the changes and introduce the market tendency in the new products that leads to customer satisfaction [1].

The automotive industry is a growing business, especially in the East Europe. In Romania, in the last years, the automotive business has brought a high number of jobs and possibilities for development in several areas (production and development) [1].

In different areas of the country we can find the final cars producers (Dacia, Ford), TIER 2 suppliers (Continental Automotive, Hella, Dura, TRW, Mahle), TIER 3 suppliers (Thomas, Dedienne, Hock). All these companies have started to grow in the automotive directions and continuous improvement based on the customer expectations [1].

According to some research performed by Mrs. Irina Hincu, senior consultant, in spite of a sharp decline in sales in the region during 2013, there is a positive outlook for 2014 in terms of automotive production. At regional level it is forecasted by the end of 2015 a 9.1\% increase in the total number of units to be produced. This positive outlook is sustained with arguments which include competitive wages, an educated and productive labor force and ongoing investment in manufacturing. However, analysts expect some car manufacturers to encounter overcapacity problems in 2015 as a result of declining sales figures in the previous year [1].

Production of passenger cars (out of total vehicles produced) in Romania, in 2013, increased by $4.3 \%$ in comparison to figures in 2012, whereas in 2014 a $9.6 \%$ increase is expected. There are two key factors favoring the positive outlook in production. Firstly, there is many companies investing in Romania and secondly, wages in the country continue to remain competitive when compared to neighboring countries [1].

Local automotive production hit a record high of 410,959 units in 2013. Out of the total production, 91\% was exported. As a result, automotive exports increased by $12 \%$ in 2013. According to APIA (Automotive Manufacturers and Importers Association), a 30\% year-on-year rise in sales of passenger cars and slight recovery in the commercial vehicles segment have been observed in the first eight months of 2014 in Romania. By comparison, last year figures highlighted a decline of $13 \%$ in passenger car sales in Romania, from 66,436 in 2012 to 57,710 units in 2013 (OICA Sales Statistics, 2013). The 2013 decline was driven by the slowdown in consumption and a sharp decline in banking credit. Another important aspect directly affecting automobile purchasing is oil price. In 2014, Romania witnessed further fuel price increases as a result of a $7 \%$ excise. Romania is reportedly the 9th member of the EU in terms of highest diesel fuel prices [1]. 
Understanding the automotive development life cycle is of paramount importance, before starting to construct any suitable tailored service process, which will be understood and accepted by the stakeholders. Effective process establishment "does not happen until an organization recognizes the need for it and the benefits it will bring them", i.e. [2]. From lessons learned, exploring any established institution or organization requires a thorough understanding of the actually applied and time-honored processes. The research of this paper is focused on the development of ECU's. Therefore, the discussion suggests that the ' $C M$ ' in automotive ECU development projects starts directly after the freeze of FRS, which is the basis of the contract between OEM and supplier. If the research aims for the complete car development process the CM process start would probably be located at the Concept Requirement-Specification freeze. However, no harm done if the CM process start to early! The real benefit of the process is to collect the data describing the RfC and guide them through all the $\mathrm{CM}$ steps necessary to prepare the information required to take the adequate decisions with the best possible confidence and benefit for the business [3].

\section{METHODOLOGY OF RESEARCH}

In automotive industry the development of new products, involve complex engineering processes subject to time pressures and fierce competition on the automotive market. An important role in the development of such projects it is the process planner. The position of process planner involves the interface between the department of design and development and production department, managing the projects in terms of technical side till implement them in series production [4].

Risk management requires the development of optional risk management plans for situations that may arise and trigger the implementation of appropriate corrective actions that we plan when a risk occurs, and this is detected and diagnosed with the cause of the risk. Risk management necessarily refers to the three life cycles generating engineering systems [4]:

- research, development, testing and evaluation;

- purchase or production of systems; and

- system planning and marketing.

Failures and crisis situations can develop because of the risks that materialize in any of these efforts. There are other organizational processes that need to undergo risk management. The three above are the ones of interest.

Based on the standards such as: IATF 16949, ISO 31000 and ISO 31010, I approached the problems occurring in series production of one sensors factory for the automotive industry.

In another case study of engineering risk in automotive industry was discussed about the engineering of risk management is placed and how its implementation has been tried in multinational companies in automotive industry from Romania. A large number of companies don't use a strategy to avoid the engineering risk in their design products [5].
Engineering risk is linked also to safety and security engineering are very closely related disciplines and could greatly benefit from one another if adequate interactions are defined. Both disciplines focus on system-wide features and should be integrated into the development process from the initial phases and onwards. Safety engineering is already an integral part of automotive engineering and safety standards are well established in the automotive industry [6].

I will further describe the sensor in question, its functionality, but also a short interdisciplinary part between serial production and the $R$ \& $D$ department. To approach this problem, we will rely on the scheme in the figure below, Figure 1.

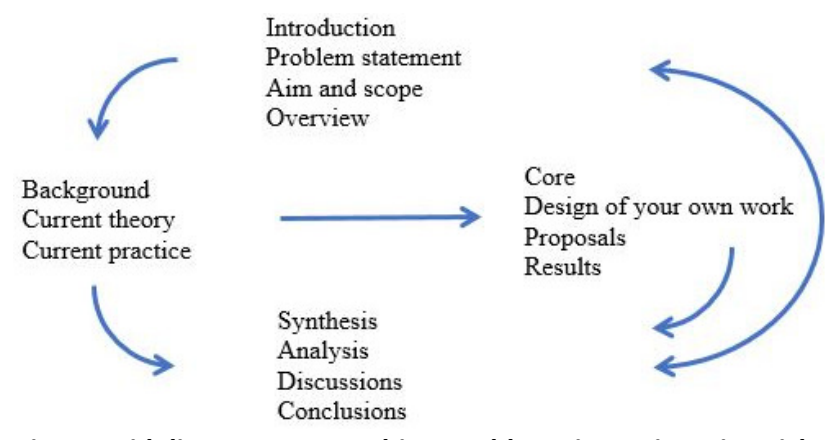

Fig. 1 Guidelines on approaching problems in engineering risk

Now we will talk about the ECU sensor with the generic name of XPU (Exchange Process Unit, or sensor called the "exchange processor"), this sensor was developed by ADAS business unit. The sensor is shown on the Figure 2.
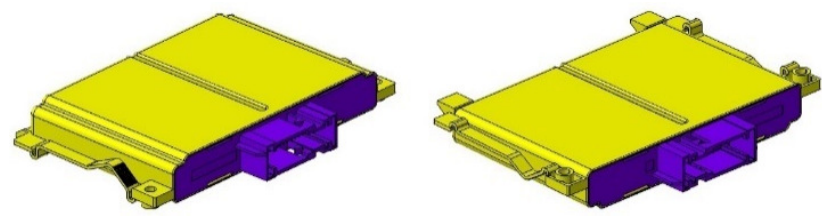

Fig. 2 XPU sensor, shown in isometric view from CAD model

The role of this sensor is to make the connection between camera sensor and the radar sensor that helps assisted driving. The connection made by this sensor is to establish communication between the sensors mentioned, but it also has the role of processing information that can come either from the camera sensor or from the radar sensor. Depending on the information gathered from the two sensors, this processor sensor also has function-based decisions in assisted management, like: autonomous braking decision, the decision to accelerate, decision to adapt to cruise speed, decision to adapt to weather conditions: rain, wet road.

Currently, two independent technological revolutions are affecting the automotive industry: on one hand, the replacement of the internal combustion engines with electric drives and, on the other hand, the automation of driving through Advanced Driver Assistance Systems (ADAS) culminating in the Autonomous Vehicle (AV). Driving a vehicle safely and reliably requires a whole variety of skills; it is not without reason that people are permitted to drive vehicles only when they reach a certain degree of maturity and after adequate training [7]. 
Majority of the sensors have a specified measurement range and signal bandwidth restrictions. Thus, it becomes hard to distinguish "intended signal" (such as obstacles in the road) and the system "noise." The level of inconvenience, for the sensors to track moving objects, takes a paradigm shift during hostile environmental conditions such as rainy and fogy conditions [8].

ADAS performance can be improved by optimizing system performance through effective sensor fusion techniques which is the coherent combination of measured data from different sensors. Hence, it is important to choose proper set of sensors for enhanced ADAS performance [8].

We will define the assembly of the sensor based on the causes that can cause problems, but also an overview. All this structure will be shown in Figure 3.

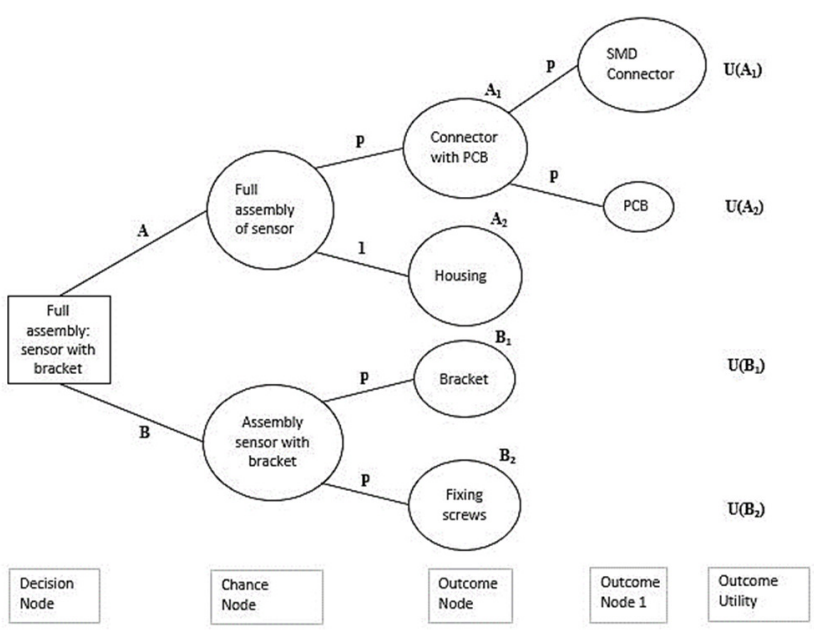

Fig. 3 A fundamental model that shows how risk decisions emerge in describing problems

On a tree structure, we present the assembly steps of the sensor. Considering that the process will follow multiple assembly steps, we will address the problems that may arise during the assembly process and the causes that have led to assembly problems.

Problems will be treated hypothetically, although problems may arise in serial production.

Problem 1. Assemble the sensor. Here we are dealing with the final stage of assembly of the processor exchange sensor. This will include the housing and the PCB on which an SMD type connector is mounted. The SMD connector is mounted with pins, paddles (without bracket or buffer). A very important feature is the tolerance to flatness, because we must have very good contact because the welding process will follow. Most problems typically arise on the soldering machine or soldering process, either due to machine problems or an external problem or due to flatness tolerances, which leads to bonding defects. Another problem that may arise is caused by the components that are part of the housing, housing or SMD connector, but these will be treated separately.

Problem 2. Following the decision node, we notice that it is embedded on a tree structure. We will stop at the intersection of events, as well as those from problem 1 . On this structure, defects can occur when assembling the sensor in support. One of the causes may be cracking around the reinforcement rib of the passage through the housing, which can cause a breakage due to failure of the screw torque. Also, here on the metal support on which the sensor is assembled, problems with the threaded inserts may occur if they have not been properly inserted into the slot intended for the sensor. If we have discussed up to now issues with decision-making, we will talk about the resulting nodes and we will continue to treat them.

Problem 3. The PCB connector, here we discussed soldering problems, but there may also be problems with PCBs in the heater, which can cause deformation, which in turn causes voltages in the PCB. Other PCB problems can be populated with components. Here a preventive action can be taken, where you can check collisions that can occur in populated.

Problem 4. Housing Although it seems an important component, there are many problems here, for example: problems with the measurement ratio, where we have dimensions that are not in line with the dimensions in the drawing, problems with the injection process where we have parameters that sometimes lead at rests, burnings of the material, in the form of bubbles, which is observed on the piece at a visual inspection. Another problem may be logistic, when the pieces are not packaged according to the specification, some deformation results.

Problem 5. The metal support where the mounted sensor will come. Here the same problems can occur as in the case, to mention that the support is made of an aluminum alloy and the case is plastic, which means we have different technologies in the process of obtaining the two components.

Problem 6. Screws. At first glance it seems the smallest problem, but there are some risks here too. These risks would be in production, but only if a moment of screwing is set over the specifications in the drawing.

Problem 3.1. This problem is a complementary issue from problem 3, where we only deal with the technical problems that may occur at the SMD connector, misalignment of the pins, non-compliance with the flatness tolerance, the ratio of measurements that can be with quotes out of the specification on the drawing.

Problem 3.2. PCB, here the problems that I have already mentioned in issue 3 can arise. It should be noted that another problem could appear at cutting the PCB with the guillotine scissors, after the whole plate after the populated.

So, I treated the node of the events, which means I reviewed the above-mentioned nodes, where we identified the problems that appear technically. These problems can also lead to financial problems if prevention actions are not taken early. If we talked about time, we identified another problem because all these lead to a chain reaction that can generate a lot of risks. All these issues that I have dealt with above have not been balanced when the process has gone through the $R \& D$ phase.

\section{What happened in the series production? What were the actions?}

In serial production, although the customer had the process launched, namely PPAP documents, there were problems with the housing stock for a production of 24,500 
sensors in 3 weeks. The problems were generated by a deformation of the casing, see Figure 4.

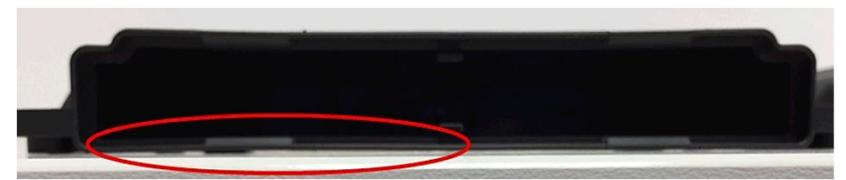

Fig. 4 Housing warpage

Since these housings were largely deformed, serial production stopped, and a risk assessment action was taken immediately. We will enumerate below:

- Is it possible to assemble the connector in the housing? - If the housing has retracted, is there no risk of destroying the components that populate the circuit board?

- Will a new tool correction be required?

Besides these deformations, burrs were visible at a visual inspection, in the area of the line of separation, which is not allowed to happen; there were also cracks visible in the piece, as we can see in Figure 5.

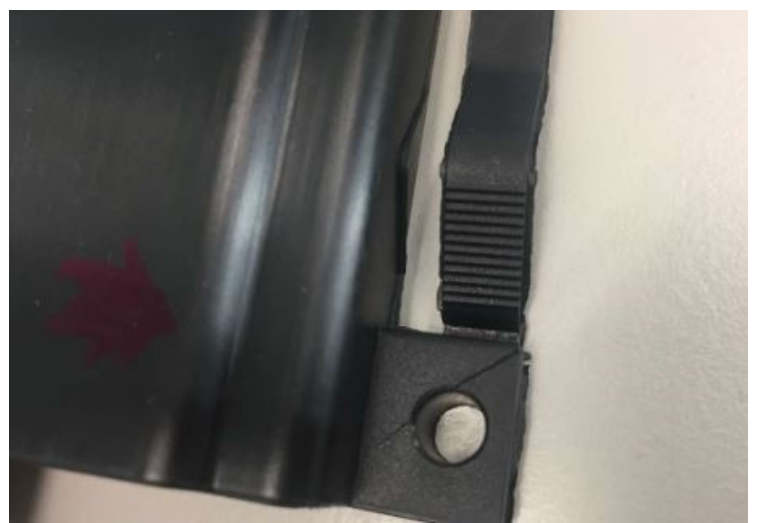

Fig. 5 Burrs and cracks on hosing

Following these issues, before carrying out the risk assessment, in Figure 6, we also see the disciplines involved:

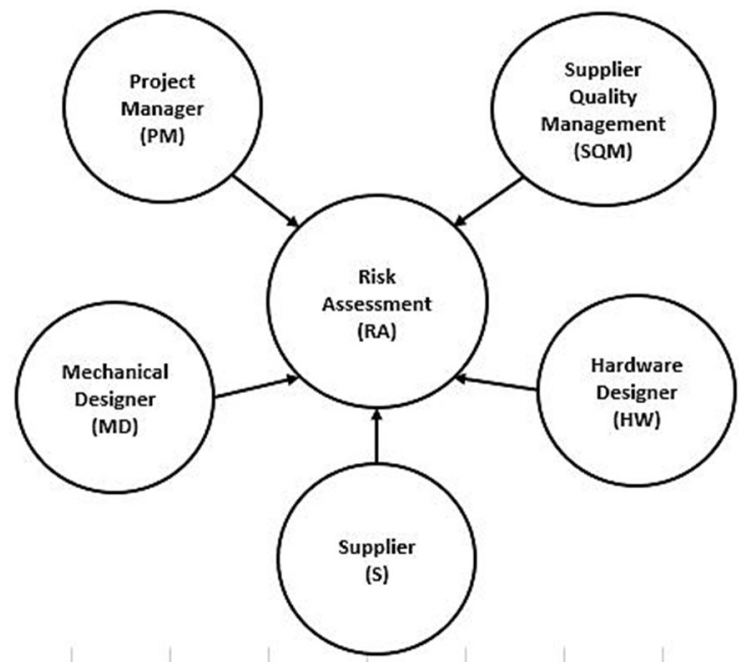

Fig. 6 Disciplines involved in the project

\section{METHOD OF RESEARCH}

The first action, from SQM (SQM, Supplier Quality Manager - which is the quality manager for the vendor), was to check the impact of the retrieval on the housing (which came in the deformed lot), namely:
1. Are there any collisions following the assembly of the housing with the components on the circuit board?

2. Can the circuit board connector in the housing be assembled?

At point 1, the risk assessment was initially made in the $\mathrm{Ca}$ tia design program, where the product also developed. We wanted to track the clearance distance between the SMD electrode components on the circuit board and the housing, to see what the risk of collisions is. We can point out here that a general rule in the assessment of these risks is the following: if the minimum distance between the two components of the same assembly is $<1 \mathrm{~mm}$, then a more detailed tolerance calculation must be performed.

The second action initiated by HW and MD was to check the clearance spacing of the largest components in the height of the circuit board and the inside of the casing, as well as the evaluation in case of a collision of the two components with the casing and the risk of breaking of the two components on the circuit board, during the sensor operation, from which, again, two cases a.) and b) arise:

a.) The clearance distance between the largest components in the height of the circuit board and the inside of the housing.

In Figure 7, we will notice the clearance distance, which is $6.1 \mathrm{~mm}$; and if we take into account the tolerances in the assembly process of $0.6 \mathrm{~mm}$ we will finally have a distance of $5.5 \mathrm{~mm}$; which means that we will not need to make a detailed calculation of tolerances.

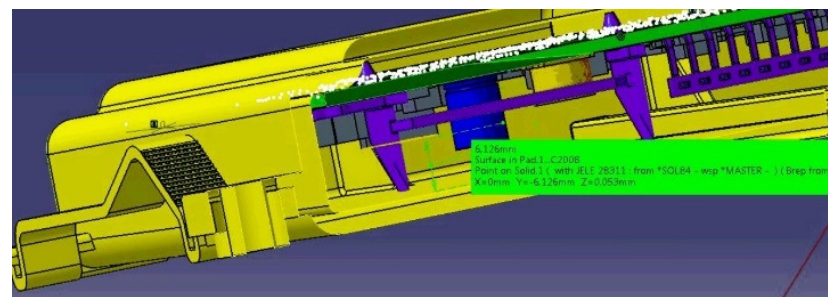

Fig. 7 Clearance distance between first highest component from $P C B$ and interior wall of housing

In Figure 8, we will notice the second largest clearance distance, which is $4.3 \mathrm{~mm}$; and if we consider the tolerances in the assembly process, we will eventually have a clearance of $3.7 \mathrm{~mm}$ from where it appears that there is no need for a thorough check or that we may have collisions.

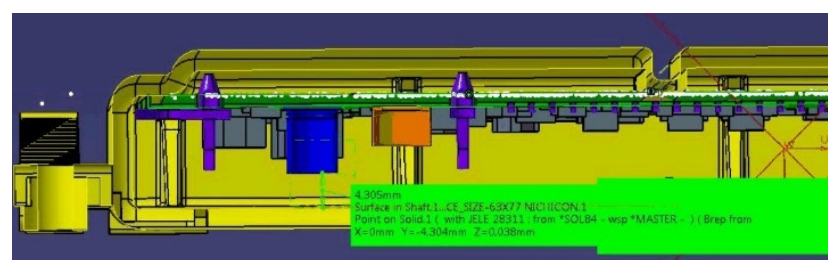

Fig. 8 Clearance distance between second highest component from $P C B$ and interior wall of housing

b.) Risk assessment in case of breakage of the two components.

It has been found that the two electronic components on the circuit board are two tantalum electrolytic capacitors (e-caps) commonly used in SMD versions at 3V3 power, which means they can power a microprocessor up to a maximum of $50 \mathrm{~mA}$. See in the electrical diagram of the Zucken 
design program, the distribution of these two capacitors in Figure 9:

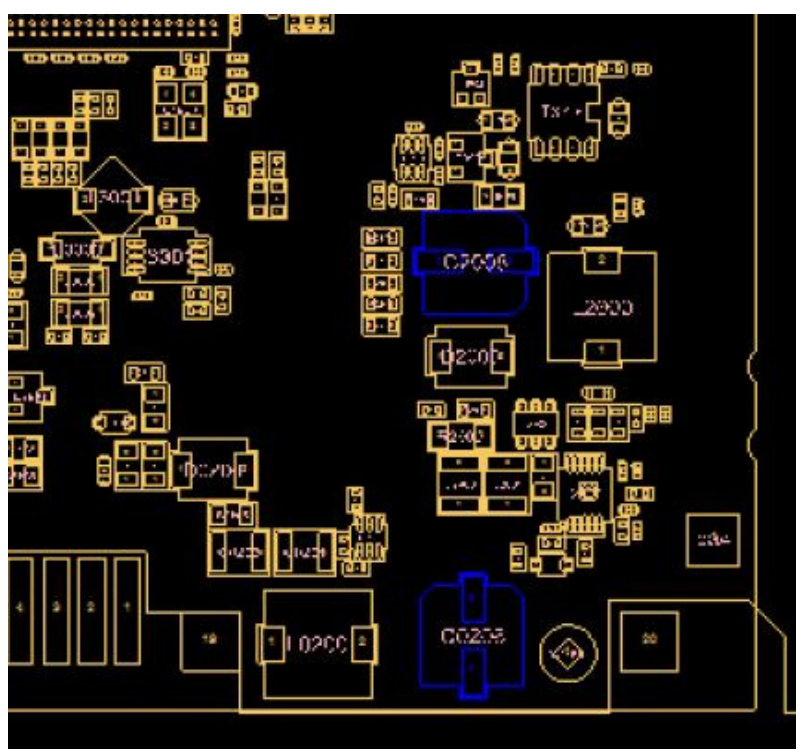

Fig. 9 The electric scheme and the representation of the two blue-green electrolytic capacitors

These types of electrolytic capacitors can provide more power, up to $500 \mathrm{~mA}$, thanks to a switching regulator. Generally, the $5 \mathrm{~V}$ supply with a $3 \mathrm{~V} 3$ controller is used for projects where $3.3 \mathrm{~V}$ is required.

Without these two electrolytic capacitors, the consequences would be the following:

- High impact of EMC radiation (No - ElectroMagnetic Compatibility, which means Electro-Magnetic Compatibility);

- Autarchy time would decrease, which means that the ECU sensor will continue to work, but the decision-making may be delayed.

The last action in dealing with these problems was whether to allow a new injection tool change. On the design engineer side, the answer was negative, because in the case of a modification of the injection tool, the modification of a dimension could lead to other deviations in the dimensions of the casing, and as a suggestion to avoid this tooling, changing of the injection parameters was proposed. The modified parameter in this case was the temperature on the plastering cylinder, more precisely the temperature in the cooling zone, which initially was $70^{\circ} \mathrm{C}$. Various tests were performed with this parameter listed above at $50^{\circ} \mathrm{C}, 55^{\circ} \mathrm{C}, 60^{\circ} \mathrm{C}, 65^{\circ} \mathrm{C}$.

For the investigation of the deviations, we used 3D scanning ATOS for scanning, interpreting and measuring them in the GOM inspect 2017 software. These interpretations were made both by the supplier and by the manufacturer of this sensor, in this case, Continental Automotive Romania SRL. The relevant results that were finally used, were those from Continental, as the supplier measured only the external deviations, not the critical dimensions on the drawing.

For this investigation, the gom ATOS 3D Scanner was used and two samples in each nest with the cooling zone temperature at $50^{\circ} \mathrm{C}, 55^{\circ} \mathrm{C}, 60^{\circ} \mathrm{C}, 65^{\circ} \mathrm{C}$. The $3 \mathrm{D}$ gom ATOS scanner will be presented in Figure 10, below:

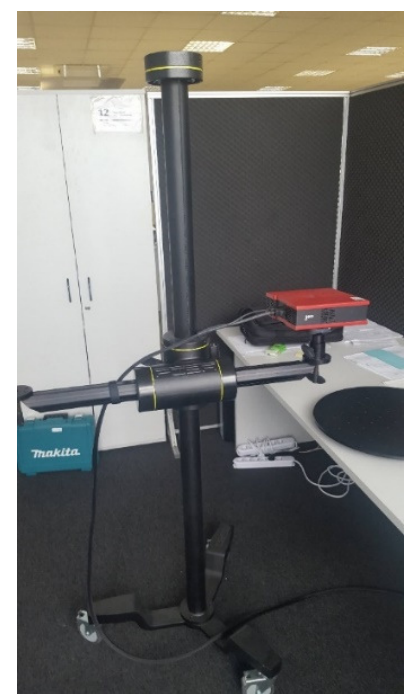

Fig. 10 Scanner 3D GOM ATOS for measurements

For the measurements of the samples, we presented just one overview with the representative deviations, the overview of this impact will be shown on the final investigation from the plant; the deviations can be seen on Figure 11.

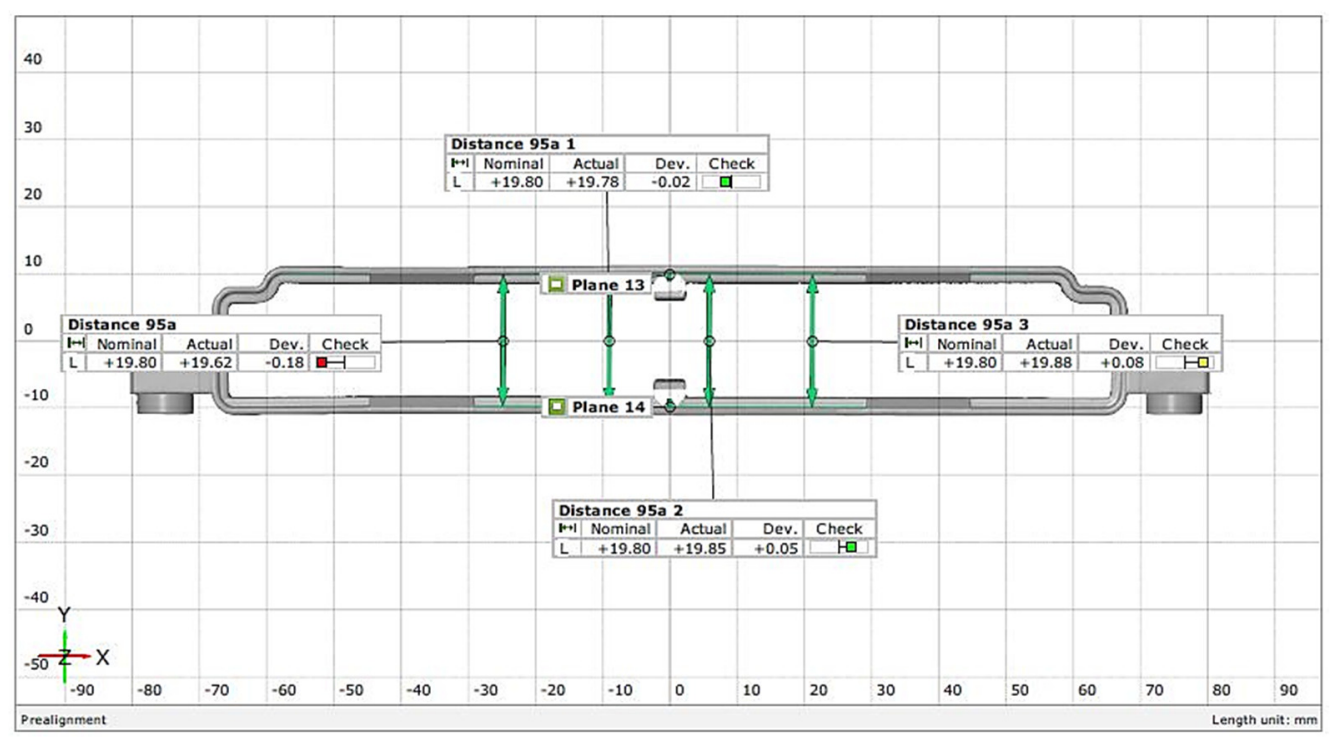

Fig. 11 Critical dimensions of the housing 
According to the findings of this report, the R\&D department wishes to go further on the no-change version of the injection tool and wants a feed-back on the part of the production, following the assembly of the multi-samples with the cooling temperature parameter at $50^{\circ} \mathrm{C}, 55^{\circ} \mathrm{C}$, $60^{\circ} \mathrm{C}$ and $65^{\circ} \mathrm{C}$.

Based on these monitors, an assembly process took place in the production, the results will be presented in the Table below:

In Table 1, we have production results from Ingolstadt, from Germany production. Several monitors were tested, namely:
- 12 monitors with the temperature in the cooling zone at $50^{\circ} \mathrm{C}$;

- 8 monitors with the temperature in the cooling zone at $55^{\circ} \mathrm{C}$;

- 10 monitors with the temperature in the cooling zone at $60^{\circ} \mathrm{C}$;

- 8 monitors with the temperature in the cooling zone at $65^{\circ} \mathrm{C}$.

The final decision will be taken by the disciplines involved, as shown in Figure 9. The decision following the assemblies of the production samples will be taken in a type of deviation approval document, see Figure 12.

Table 1

Results from production after assembly process

\begin{tabular}{|c|c|c|c|c|c|c|c|c|c|c|c|c|c|c|c|c|}
\hline 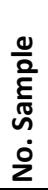 & 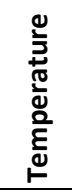 & $\frac{\bar{y}}{\frac{\tilde{y}}{\tilde{\alpha}}}$ & $\begin{array}{l}\bar{y} \\
\text { O } \\
\underline{1} \\
\underline{\mathbb{1}}\end{array}$ & 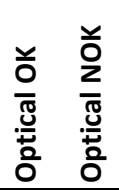 & $\begin{array}{l}\dot{0} \\
\frac{1}{\pi} \\
\frac{1}{0}\end{array}$ & 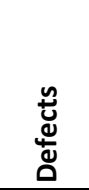 & $\begin{array}{l}\dot{\xi} \\
\text { छे }\end{array}$ & 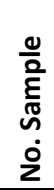 & 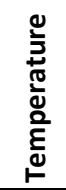 & $\frac{\bar{y}}{\frac{0}{n}}$ & 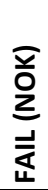 & $\frac{\text { 0. }}{\frac{0}{0}}$ & 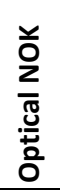 & $\begin{array}{l}\dot{0} \\
\frac{7}{\pi} \\
0\end{array}$ & 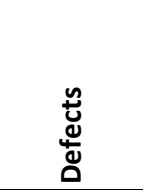 & $\begin{array}{l}\dot{\varepsilon} \\
\dot{\varepsilon} \\
\dot{\jmath}\end{array}$ \\
\hline 1 & $50^{\circ}$ & $x$ & & & 200151597 & & & 20 & $55^{\circ}$ & $x$ & & & & 200151481 & & \\
\hline 2 & $50^{\circ}$ & $x$ & & & 200151600 & & & 21 & $60^{\circ}$ & & $x$ & & & 200151648 & Label & Label \\
\hline 3 & $50^{\circ}$ & & $x$ & & 200151667 & Label & Label & 22 & $60^{\circ}$ & & $x$ & & & 200151626 & Label & Label \\
\hline 4 & $50^{\circ}$ & $x$ & & & 200151679 & & & 23 & $60^{\circ}$ & & $x$ & & & 200151635 & Label & Label \\
\hline 5 & $50^{\circ}$ & $x$ & & & 200151668 & & & 24 & $60^{\circ}$ & $x$ & & & & 200151602 & & \\
\hline 6 & $50^{\circ}$ & $x$ & & & 200151696 & & & 25 & $60^{\circ}$ & $x$ & & & & 200151637 & & \\
\hline 7 & $50^{\circ}$ & $x$ & & & 200151680 & & & 26 & $60^{\circ}$ & $x$ & & & & 200151636 & & \\
\hline 8 & $50^{\circ}$ & $x$ & & & 200151678 & & & 27 & $60^{\circ}$ & $x$ & & & & 200151647 & & \\
\hline 9 & $50^{\circ}$ & $x$ & & & 200151695 & & & 28 & $60^{\circ}$ & $x$ & & & & 200151590 & & \\
\hline 10 & $50^{\circ}$ & $x$ & & & 200151697 & & & 29 & $60^{\circ}$ & $x$ & & & & 200151589 & & \\
\hline 11 & $50^{\circ}$ & $x$ & & & 200151698 & & & 30 & $60^{\circ}$ & $x$ & & & & 200151638 & & \\
\hline 12 & $50^{\circ}$ & $x$ & & & 200151677 & & & 31 & $65^{\circ}$ & $x$ & & & & 200234562 & & \\
\hline 13 & $55^{\circ}$ & $x$ & & & 200151579 & & & 32 & $65^{\circ}$ & $x$ & & & & 200234831 & & \\
\hline 14 & $55^{\circ}$ & $x$ & & & 200234832 & & & 33 & $65^{\circ}$ & $x$ & & & & 200151577 & & \\
\hline 15 & $55^{\circ}$ & $x$ & & & 200151598 & & & 34 & $65^{\circ}$ & & $x$ & $x$ & & 200234561 & Flash Apl. & Flash \\
\hline 16 & $55^{\circ}$ & & $x$ & & 200151482 & Label & Label & 35 & $65^{\circ}$ & $x$ & & $x$ & & 200151578 & & \\
\hline 17 & $55^{\circ}$ & $x$ & & & 200151580 & & & 36 & $65^{\circ}$ & $x$ & & $x$ & & 200151625 & & \\
\hline 18 & $55^{\circ}$ & $x$ & & & 200151599 & & & 37 & $65^{\circ}$ & $x$ & & $x$ & & 200151649 & & \\
\hline 19 & $55^{\circ}$ & $x$ & & & 200151601 & & & 38 & $65^{\circ}$ & $x$ & & $x$ & & 200151650 & & \\
\hline
\end{tabular}

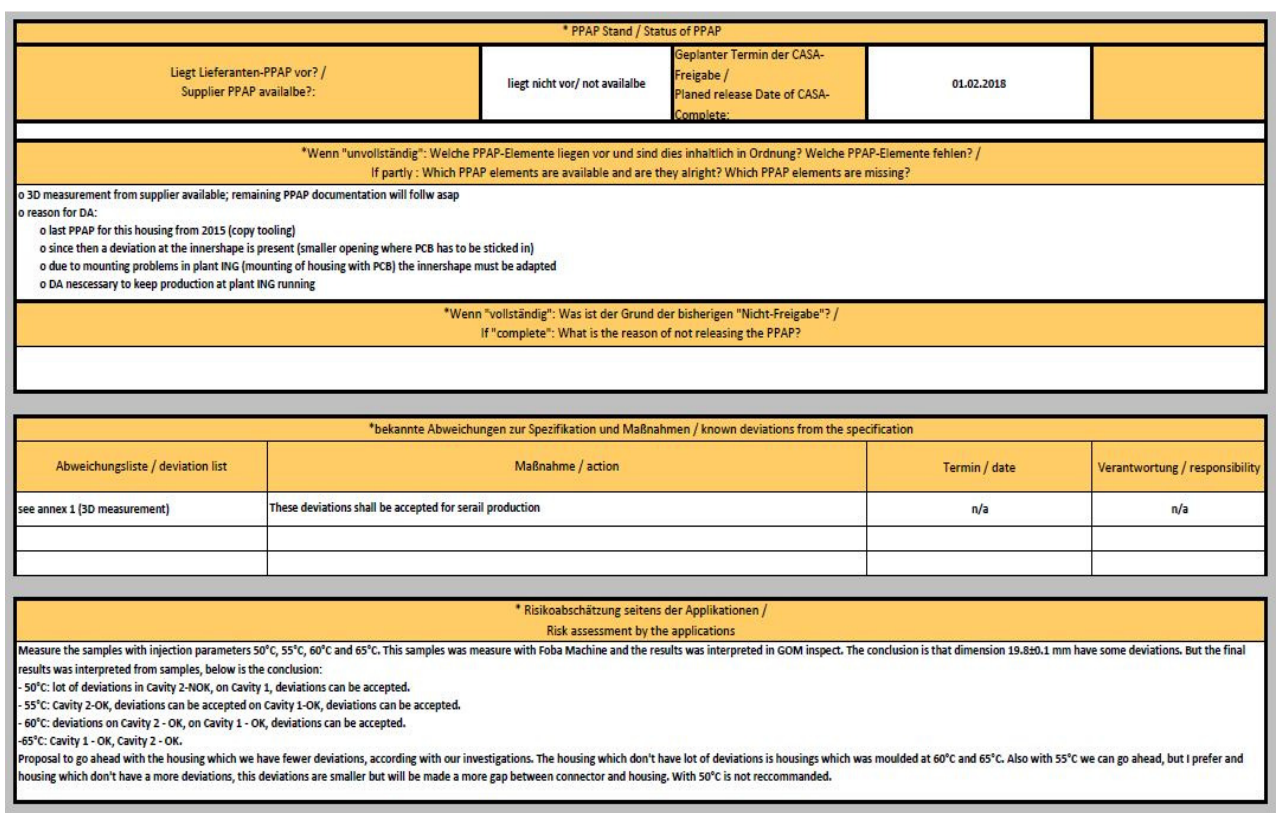

Fig. 12 List with deviation approval 
These issues pose risk to supply chains since their occurrence may through e.g. reputational losses cause adverse stakeholder reactions. Despite the growing importance of supplier management as a key process within supply chains and the frequently articulated demand for a quantitative assessment of associated risks, such approaches are missing so far [9].

\section{CONCLUSIONS}

Samples with temperature in the cooling range of $50^{\circ} \mathrm{C}$, $55^{\circ} \mathrm{C}, 60^{\circ} \mathrm{C}$ and $65^{\circ} \mathrm{C}$ were measured. These monitors were measured with the 3D GOM ATOS scanner, and the results were interpreted in the GOM inspect software. The conclusion is that the dimensions of $19.8 \pm 0.1 \mathrm{~mm}$ have some deviations. But the results were interpreted with the help of some monitors, and I took into consideration the following conclusions:

- $\quad 50^{\circ} \mathrm{C}$ : a lot of deviations in the 2-NOK Cavity, on Cavity 1 , deviations can be accepted.

- $55^{\circ} \mathrm{C}$ : Cavity 2-OK, deviations can be accepted at Cavity 1 - OK, deviations can be accepted.

- $60^{\circ} \mathrm{C}$ : Deviations on Cavity 2 - OK, on Cavity 1 - OK, deviations can be accepted.

- $65^{\circ} \mathrm{C}$ : Cavity 1 - OK, Cavity 2 - OK.

The proposal to go further with the housings with fewer deviations, according to the investigation. The housing that does not have many deviations is the case that had the parameter changed to $60^{\circ} \mathrm{C}$ and $65^{\circ} \mathrm{C}$. Also, with the parameter of $55^{\circ} \mathrm{C}$ we can go further, but preferably the housings that have fewer deviations. With the $50^{\circ} \mathrm{C}$ parameter it is not recommended to go into serial production.

\section{ACKNOWLEDGEMENT}

This article is based on results of the project bracket XPU3XX_SERIES_Project financed from Approval Budget of Project brackets by Continental Automotive Romania $S R L$.

\section{REFERENCES}

[1] C.G. Lixandru. "Supplier Quality Management for Component Introduction in the Automotive Industry", in Proc. of 13th International Symposium in Management, Management During and After the Economic Crisis, vol. 221, 2016, pp. 423-432.

\section{Dipl. Eng. Dan Mihai Popa}

Politehnica University of Timisoara

Bd. Mihai Viteazu no. 1, 300222, Timisoara, Romania

tel.: +40 256403591

e-mail: danmihai.popa@student.upt.ro
[2] S. Lacy and I. Macfarlane. Service Transition. London: The Stationery Office, 2007.

[3] S. Volker and G. Prostean. "Research of Automotive Change Management and Combined RiskManagement Models", in Proc. of 13th International Symposium in Management, Management During and After the Economic Crisis, vol. 221, 2016, pp. 395-404.

[4] L. Margineanu, G. Prostean and S. Popa. "Conceptual model of management in automotive projects", in Proc. of 7th World Conference on Educational Sciences, vol. 197, 2015, pp. 13991402.

[5] D.M. Popa. "Case study of engineering risk in automotive industry". Management Systems in Production Engineering, vol. 26, no. 1, pp. 27-30, 2018.

[6] G. Macher, E. Armengaud, E. Brenner and C. Kreiner. "Threat and Risk Assessment Methodologies in the Automotive Domain", in Proc. of 1st Workshop on Safety \& Security Assurance for Critical Infrastructures Protection (S4CIP), vol. 83, 2016, pp. 1288-1294.

[7] T. Dörfler. "Testing ADAS sensors in early development phases". ATZelektronik worldwide, vol. 13, no. 1, pp. 54-57, Feb. 2018.

[8] J.K. Baruah, R. Bera and S. Dhar. "Ranking of Sensors for ADAS-An MCDM-Based Approach", in Advances in Communication, Devices and Networking. R. Bera, S.K. Sarkar and S. Chakraborty, Eds. Singapore: Springer, 2018, pp. 563571.

[9] K. Zimmer, M. Fröhling, P. Breun and F. Schultmann. "Assessing social risks of global supply chains: a quantitative analytical approach and its application to supplier selection in the German automotive industry". Journal of Cleaner Production, vol. 149, pp. 96-100, 2017. 